\title{
Study on the Removal of Fluorescent Whitening Agent for Paper-mill Wastewater Reuse using the Submerged Membrane Bioreactor (SMBR) with Ozone Oxidation Process
}

\author{
Jang-Seung Choi ${ }^{1}$, Seung-Han Ryu ${ }^{1}$, Dong-Hoon Shin ${ }^{1}$, Jae-Young Ryu ${ }^{2}$, Won-Sik Shin ${ }^{3}$, Min-Soo \\ Park ${ }^{4}$, Jin-Ho Kim ${ }^{4}$, Jae-Eun Heo ${ }^{5, *}$ \\ ${ }^{1}$ Korea Dyeing and Finishing Technology Institude(DYETEC), Daegu, Republic of Korea \\ ${ }^{2}$ Department of Environmental Engineering, Kyungnam University, Masan, Republic of Korea \\ ${ }^{3}$ Department of Environmental Engineering, Kyungpook National University, Daegu, Republic of Korea \\ ${ }^{4}$ Econity Co. Ltd., Yongin, Republic of Korea \\ ${ }^{5}$ Ecoplus Co. Ltd., Cheonan, Republic of Korea \\ *Corresponding author: Tel.: +82 41 5223903. E-mail: kmuweb@gmail.com
}

\begin{abstract}
In this study, effluent water was produced through Submerged Membrane Bio-Reactor (SMBR) process, which is a simple system and decomposes organic matter contained in wastewater with biological treatment process and performs solid-liquid separation, Especially, ozone oxidation treatment process is applied to effluent water containing fluorescent whitening agent, which is a trace pollutant which is not removed by biological treatment, and influences the quality of reused water. The concentration of COD in the SMBR was $449.3 \mathrm{mg} / \ell-\mathrm{COD}$, and the concentration of permeate water was $100.3 \mathrm{mg} / \ell$-COD. The removal efficiency was about $70.1 \%$. The amount of ozone re- quired for the removal of the fluorescent whitening agent in the permeated water in SMBR was $6.67 \mathrm{~g}-\mathrm{O}_{3} / \mathrm{min}$, and the amount of ozone required to remove COD relative to the permeate water was calculated to remove 0.997 $\mathrm{mg}-\mathrm{COD}$ for $1 \mathrm{mg}$ of $\mathrm{O}_{3}$.
\end{abstract}

Keywords: membrane bio-reactor (MBR); ozone oxidation; paper and papermill; fluorescent whitening agents; water reuse

\section{Introduction}

In the environmental aspect, when considering the reality that the necessity of acquiring water resource is becoming higher due to the expansion of using water resource in various areas, it is a fact and it is necessary to reuse wastewater that occurs stably in the quantitative aspect. According to UN, almost half of the population of the whole world will lack be living in the areas with lack of water in 2030 due to global warming. It is also foreseen that the development goals and economic activity will be implemented as risk factors if there is no continuous investment on the water facilities[1].

Especially, the average precipitation amount during 1 year in South Korea is $1,341 \mathrm{~mm}$, which is $880 \mathrm{~m}$ more than the global average, but the precipitation amount per 1 person is around $13 \%$ of the global average due to the high population[2], and the rain is only focused during June to August where interest has been increasing globally on the technical development of reusing replaceable water resource.

Fiber dyeing industry and paper-ill industry are energy and water consumption industries. The fluorescent pigments and fluorescent whitening agent make the product look white and remove the discoloration, playing the role of raising the value of the product. Until now, the pigment and whitening agent have been used widely by being applied to various consumables such as paper, detergent, hygiene 
products, textile, plastic, and paint[3]. It has been reported for the influence on the fluorescent pigments and fluorescent whitening agent that decomposition is not done well and that there is possibility of residue. However, the concentration from river or lake is not that high where it has been evaluated to not have significant influence, but there has been increase in the focus on the exposure of fluorescent pigments and fluorescent whitening agent[4].

Submerged MBR (Membrane Bio-Reactor) processing can acquire outstanding water quality where it is a focused processing method in the waster water treatment among the membrane separation process. Especially, the process applied membrane to the biological wastewater processing of the MBR method with the strengths of high-water quality stability to apply to the present industrial wastewater, small sewer, treated water supply, excrement handling, filtration regeneration, and etc. The domestic water treatment separation membrane technology is applied to sewer and some industrial facilities of village units when compared to the technology in advanced countries. Therefore, the domestic technology can be seen as the initial stage and it is grasped to have great difference with the advanced countries in the operation and control technology fields of separation membrane.

In this context, the advanced oxidation process (AOPs) is the water treatment technology to remove the harmful pollutions that cannot be processed with the existing technology due to low biodegradation or high chemical stability[5] and it displays excellent effect in controlling the slightest number of contaminants. Therefore, this study applied the submerged membrane bioreactor system to separate the organic matter included in the wastewater, acquired high quality effluent water through the SMBR, and evaluated the water quality characteristic on the SMBR treatment high quality. Furthermore, the decomposition characteristic of fluorescent pigments and the water quality characteristic of the paper-mill wastewater were evaluated by introducing the ozonation process on the effluent water including the fluorescent whitening agent.

\section{Theoretical Background}

\subsection{Submerged Membrane Bioreactor Process}

Submerged membrane bioreactor system is simple and it has the strength to reduce the power costs. The processing efficiency is very excellent and the treated water can be used as wastewater[6].

SMBR process is used in substitution for the final settling tank where complete solid/liquid separation is possible in the final stage, and it has the strength toe maintain high concentration for the microorganisms in side the bioreactor. Due to the strengths of reusing treated water, removing salts and organic matters, automation and minimization, and acquisition of treated water quality, the process has been receiving interest. Especially, many commercialization plants have been composed in the treated water supply, sewage treatment facilities, and advancement of treated water quality. However, as a method being researched to overcome the weakness of membrane separation process, the submerged membrane module was directly submerged to the aeration tank to give shear stress to the surface of the separation membrane by creating up-flow at the same time of supplying oxygen to the microorganism to prevent pollution of the separation membrane. Also, the filtrated water absorption pump was used to compress the leaking part for acquisition. Here, the normal membrane penetration pressure is operated in below 0.5 bar[7]. Also, it is operated in the biological endogenic respiration phase where there is less surplus sludge[8] and the costs consumed for dehydration can be reduced. The submerged separation membrane has to withstand the serious shearing force that occurs due to the up-flow of the air and water where very flexible material has to be used. Rather than polysulfone, it is recommended to use flexible materials such as Polyethylene (PE) and Polypropylene (PP).

SMBR method is more effective in the aspect of water quality improvement and site area in contrast to the existing activated sludge process, but it is not effective in the economic aspect. To reduce the installation fee and operation fee, it is required to develop technology to reduce installation and operation costs by reducing costs for drugs, costs of energy, direct service of reactor, and improvement of separation membrane and module[9]. 
Therefore, the process using the separation membrane is more effective to respond flexible to the water quality regulation than the conventional type, and it is evaluated to operate the system efficiently. Also, to match the water quality regulation that is becoming stricter due to the increase of water consumption due to urbanization and population increase, it is expected that the separation membrane technology will continuously increase.

\subsection{Ozone Oxidation}

The ozone is a strong oxidizing agent with high oxidation potential (2.08 eVolt)[10] and it creates quick oxidation reaction with organic and non-organic substances of various forms due to its unique molecular structure. The ozone is very unstable in the water and it self-decomposes due to cyclic chain reaction to go through middle products such as Hydroperoxide radical, Superoxide radical, and Ozonide radical to create $\mathrm{OH}$ radical with greater reactiveness. The organic matters that exist in the water can be decomposed through indirect reaction pathway that responds to $\mathrm{OH}$ radical and the direct reaction pathway that can directly remove the organic substances. The organic substance forms the ozonide due to the direct and indirect reaction to be decomposed with the aldehyde and simple organic substances to completely oxidize to water and carbon dioxide[11].

\subsection{Fluorescent Whitening Agents}

Fluorescent pigments and fluorescent whitening agents use oxidation and reducing agents to make the textiles (fiber, paper, pulp, and etc.) white. The fluorescent whitening agent treatment is executed because the small portion of yellowish brown cannot be completely removed in this kind of bleach[12,13]. The cellulose fluorescent whitening agent used in the fiber and paper-mill industry mostly use diaminostilbene disulfonic acid derivatives. The chemical structure is shown in Figure 1. Stilbene fluorescent whitening agent are used as bistriazinyl derivates of 4, 4 -diaminostilbene-2, $2^{`}$-disulphonic acid and the soluble fluorescent whitening agent substances are stilbene derivatives[14].

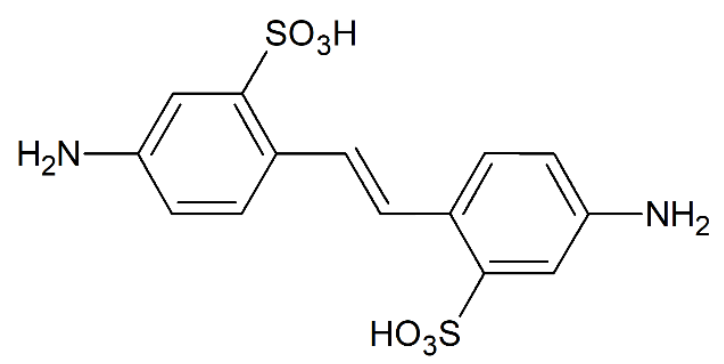

Figure 1. Chemical structure of diaminostilbene disulfonic acid

\section{Experiment}

\subsection{Subject Wastewater}

The actual wastewater used int his study is the primary chemical treated water of Company $\mathrm{M}$ in Daegu Metropolitan City, and the composition is shown in Table 1. The Company M paper-mill waste used the diaminostilbene disulfonic acid derivative used in the paper-mill industry for the composition process. The fluorescent whitening agent of the diaminostilbene disulfonic acid derivative is included in the waste where it was included in the SMBR bioreactor for operation. Based on the leakage number of the SMBR bioreactor, the optimal operation factor of the ozone oxidation was calculated for high quality of the effluent water through the membrane penetration number through the ozone oxidation including the small number of diaminostilbene disulfonic acid fluorescent whitening agent 
Table 1. Characteristics of paper \& papermill wastewater

\begin{tabular}{|c|c|}
\hline Parameter & Concentration \\
\hline $\operatorname{COD}(\mathrm{mg} / \ell)$ & $314 \sim 598$ \\
\hline $\mathrm{TOC}(\mathrm{mg} / \ell)$ & $32.0 \sim 64.4$ (SMBR Treated) \\
\hline $\mathrm{MLSS}(\mathrm{mg} / \ell)$ & $2228 \sim 3974$ \\
\hline Turbidity $($ Unit $)$ & $222 \sim 485$ \\
\hline
\end{tabular}

\subsection{Experimental Device}

The SMBR composition, as seen in Figure 2, is composed of feed tank, raw, tank, submerged membrane aerobic tank, and permeate tank. The capacity of the SMBR reactor rank is $650 \ell$ of pilot plant. To acquire stability of the process operation, $12 \mathrm{~min}$ of absorption, $3 \mathrm{~min}$ of stop, and 15 seconds of back washing consecutive operation methods were adopted. It was installed within the site of Company M's paper-mill waste treatment.

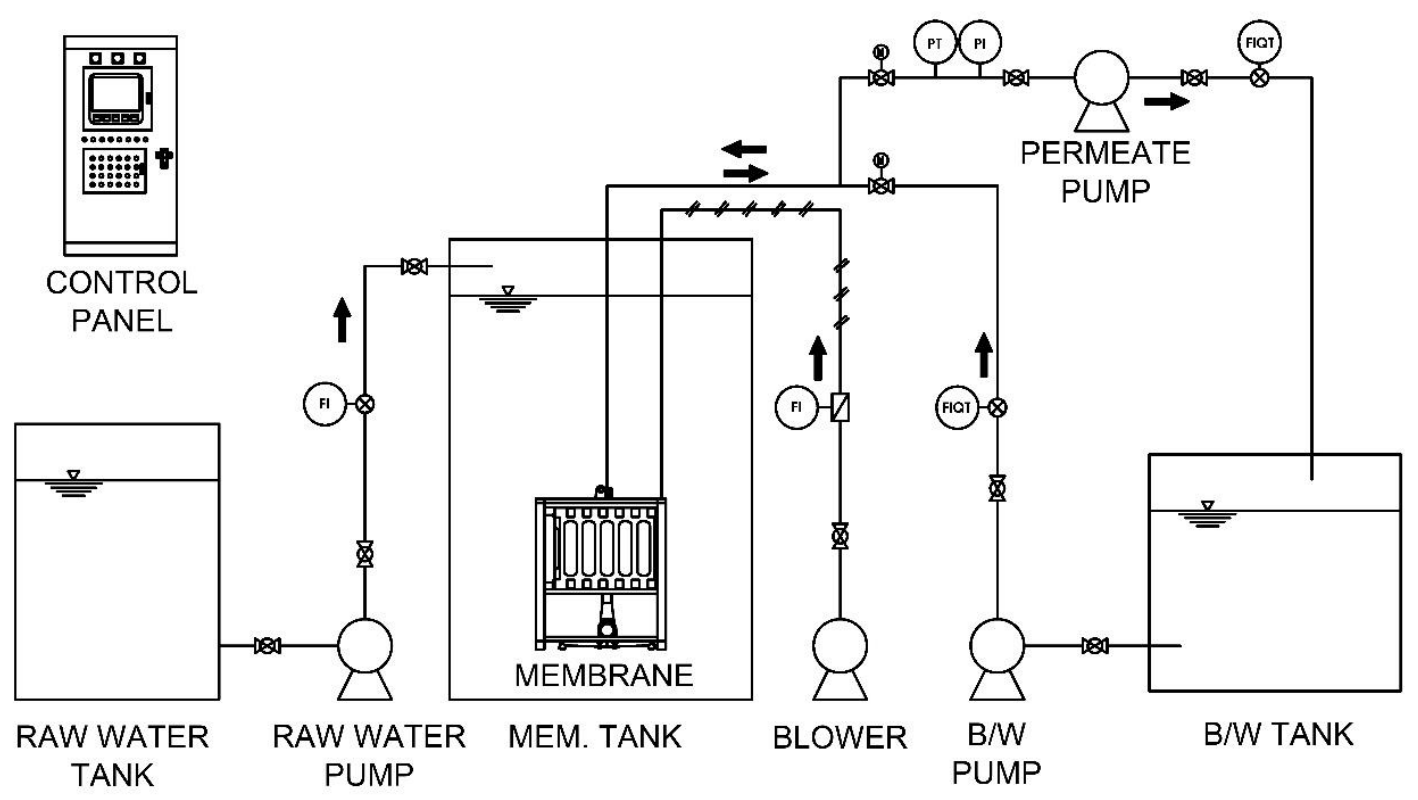

Figure 2. Schematic diagram of SMBR system

Generally, the SMBR process operation can produce reuse of high quality even in less than 4 days of SRT (Sludge Retention Time) and 2 hours of HRT (Hydraulic Retention Time)[15]. The hydraulic retention time was $4.4 \mathrm{hrs}$ and the SRT was 6.6 days for the submerged membrane aerobic used in this experiment. The separation membrane used in this research was Company E's submerged fiber membrane (CF-C Type, Korea) and the membrane module specification is shown in Table 2. The ozone oxidation device (HIO-600, Korea) was used to evaluate the decomposition process on the fluorescent whitening agent. The operation condition is as shown in Table 3. Also, for high quality of effluent water, ozone oxidation experiment was processed on the SMBR treated water. Ozone oxidation reactor tank is in the structure to maximize contact efficiency of the ozone and the wastewater. Consecutive reactor tank of the 
ozone contact tank, ozone oxidation reactor tank for stabilization of the residual ozone after contact, and the treatment tank was used, and the structure of the reactor tank is shown in Figure 3.

Table 2. Specification of membrane module

\begin{tabular}{|c|c|}
\hline Parameter & Condition \\
\hline System Type & Submerged \\
\hline Material & HDPE \\
\hline Membrane Type & Hollow Fiber \\
\hline Pore Size & $0.4 \mu \mathrm{m}$ \\
\hline Total Membrane Surface Area & $16.8 \mathrm{~m} 2$ \\
\hline
\end{tabular}

Table 3. Operation condition of SMBR

\begin{tabular}{|c|c|}
\hline Parameter & Operation Condition \\
\hline HRT & $4.4 \mathrm{hrs}$ \\
\hline SRT & 4.7 day \\
\hline Aeration Retention & $25 \sim 50 \mathrm{~m} 3 / \mathrm{min}$ \\
\hline Dissolved Oxygen & $4.0 \sim 5.0 \mathrm{mg} / \ell$ \\
\hline Temperature & $25 \pm 2^{\circ} \mathrm{C}$ \\
\hline $\mathrm{pH}$ & $7.0 \sim 8.0$ \\
\hline
\end{tabular}

In the case of Advanced Oxidation Process (AOP), $3 \mathrm{mg} / \mathrm{L}$ of ozone led to the acquisition of $2 \log$ of total of colon bacillus removal efficiency[16]. By adopting the ozone processing to the high quality of the wastewater reuse, it is judged to help the water quality of reused water and also remove the fluorescent whitening agent.

The ozone generator used in the ozone oxidation experiment uses the double derivatives to create high-concentration ozone of high-purity state to apply the ozone generator for $2 \mathrm{l} / \mathrm{min}$ of oxygen flow and ozone concentration of $166 \mathrm{~g}-\mathrm{O}_{3} / \mathrm{m}^{3}$. The ozone amount used in the experiment was $20.0 \mathrm{~g}-\mathrm{O}_{3} / \mathrm{hr}$. Figure 3 shows the consecutive ozone oxidation reactor used in the experiment. The wastewater flow went through strong oxidation process through wastewater and ozone contact by being transferred to the ozone contact tank. Then, it was moved to the ozone oxidation device to process residual ozone in the wastewater where the non-responsive ozone of the gas is discharged to air after stabilizing from the ozone processor. The wastewater completed of ozone oxidation reaction was moved to the treatment water tank to repeat the circulation process. 


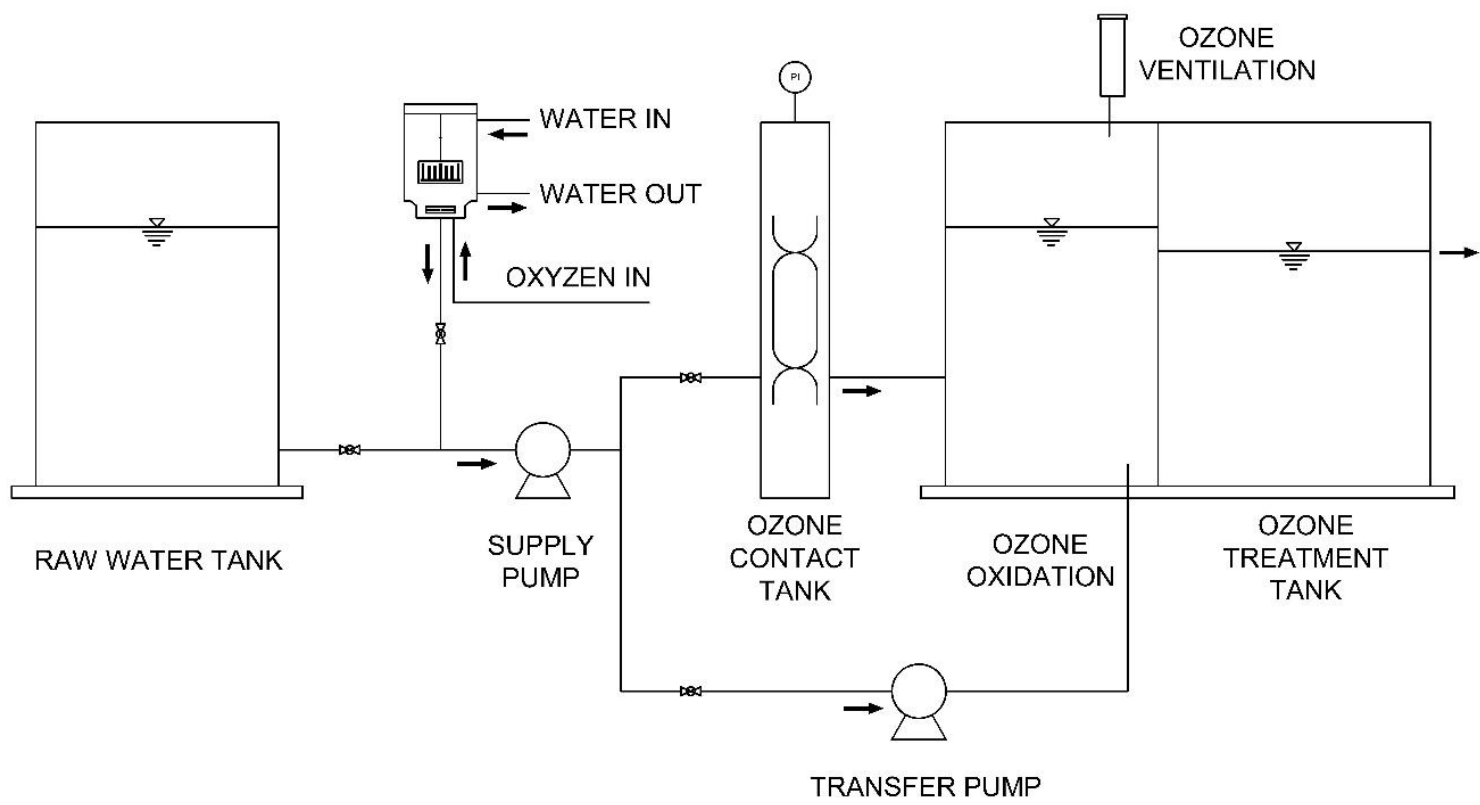

Figure 3. Schematic diagram of pilot plant ozone oxidation reactor

\subsection{Measured Items and Analysis}

This study analyzed COD, TOC, Turbidity, MLSS (Mixed Liquor Suspended Solid), $\mathrm{UV}_{254}$ Scan to evaluate on the SMBR treatment water quality and ozone treatment. The analysis method on the water quality was measured through Standard Methods[17].

\section{Result and Consideration}

The SMBR reactor operation condition during the period of experiment was MLSS 2,229 $\pm 3,937$ $\mathrm{mg} / \mathrm{L}$, aeration strength was $25 \sim 50 \mathrm{~m}^{3} / \mathrm{min}$, HRT was $4.4 \mathrm{hrs}$ and SRT was 6.5 days. It was installed within the waste treatment site of Company $\mathrm{M}$ for operation. The primary treated water of Company $\mathrm{M}$ was experimented. The HRT was operated as $4.4 \mathrm{hrs}$ due to factors such as increase of differential pressure due to concentration of MLSS and inflow of substances within the pump.

The acid radical device to prevent and clean the membrane pollution was in the structure to prevent membrane pollution due to the up-flow air supplied from the acid radical device equipped to the Econity CF-C type cartridge, which was an acid radical device designed to remove the membrane pollution due to the increasing inflow and pressure of the air.

\subsection{Change of Penetration Velocity to the SMBR Bioreactor on the Paper-mill Wastewater}

The change of the penetration velocity was reviewed on the membrane module within the SMBR reactor, and it is shown in Figure 4. The cleaning time was set and the penetration flow was set to 1.5 $\ell / \mathrm{min}$. Here, the initial differential pressure started at -0.032 bar and differential pressure increase occurred due to the membrane pollution according to the operation. However, when the differential was set to -0.070 bar, the cleaning and back washing cycle was increased to maintain -0.032 bar for differential pressure.

The initial differential pressure was -0.032 bar when setting the flow to $1.5 \mathrm{l} / \mathrm{min}$ when starting the research, but there was around $2 \sim 8 \%$ change in the case of the flow up to 5 days after membrane contamination stated. Here, the change of flux reduced by $5 \sim 8.5 \%$. This means that various subsidiary materials are used in the process of advancing the quality of the product in the paper manufacturing 
process. Especially, BOD and COD inducement substances are used with mucoid start or C-stein in the coating process and high-molecular substance such as alum in the line. Due to these substances, they are implemented as factors that influence the membrane flux when operating SMBR. Along with the influence to the membrane penetration performance with serious change of the lower layer of the membrane surface of the polymer used in the process as the cause of membrane contamination[18], the microorganism proliferation speed increases due to the increase of MLSS within the SMBR reactor rank where it has the same result as the study that reported the increase of microorganisms can become the factor of membrane contamination[19]. Therefore, when applying SMBR of paper-mill wastewater, it is needed to set the back-wash cycle to prevent membrane contamination rather than the general wastewater standard.

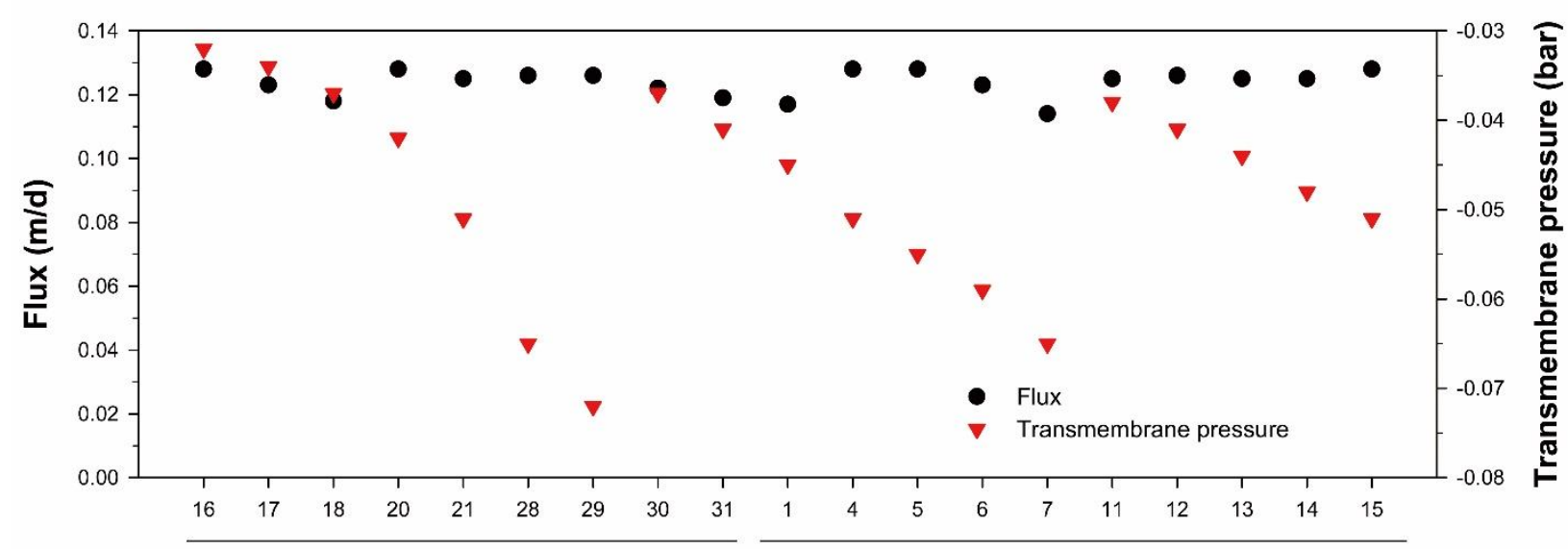

August

September

Figure 4. Variation of flux during the operating days

\subsection{Change of Organic Contamination on the SMBR Bioreactor on the Paper-Mill Wastewater}

\subsubsection{Change of Turbidity on the SMBR Bioreactor}

The turbidity of the effluent and the influent were analyzed during the period of operation of the SMBR reactor rank. Figure 5 shows the change of the turbidity according to the operation of SMBR. The minimum and maximum turbidity value of the influent was 225.0 485.0 where the average turbidity was analyzed to 327 NTU (Nepthelometric Turbidity Unit). The turbidity of the SMBR bioreactor penetration water was $0.4 \sim 2.1 \mathrm{NTU}$ for the minimum/maximum value, average of $1.1 \mathrm{NTU}$. It has appeared that the average was below 3 NTU during the operation of the SMBR reactor tank from the start of the operation. The average turbidity removal rate was more than $99 \%$. This means that the large separation was effective due to the submerged fiber membrane reactor. 


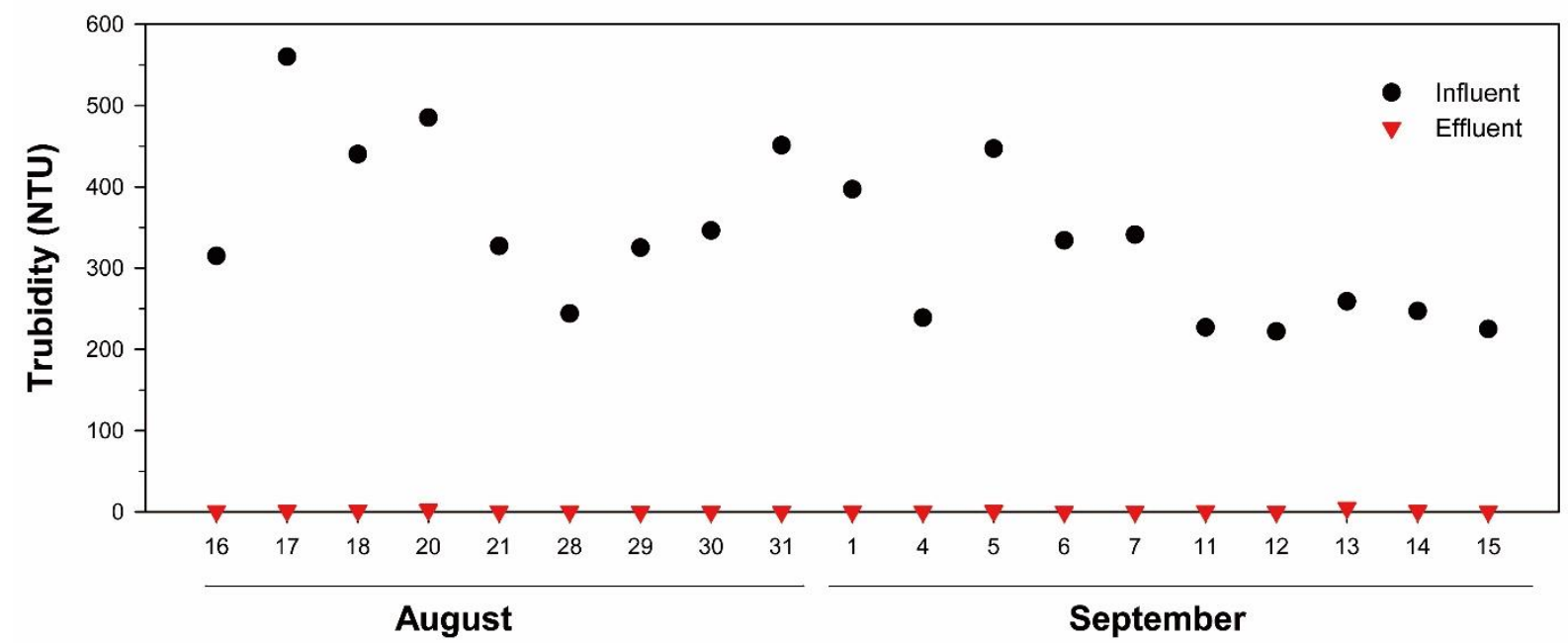

Figure 5. Turbidity of paper-mill wastewater and permeate water

\subsubsection{Change of COD on the SMBR Bioreactor}

Figure 6 is the experiment result that shows the COD concentration change of the SMBR effluent according to the HRT change in the SMBR process. The minimum/maximum value of the SMBR influence was $314 \sim 598 \mathrm{mg}$ and the average COD concentration was analyzed to be $449.3 \mathrm{mg} / \ell$. The COD concentration on the water quality that went through biotreatment in the SMBR bioreactor was minimum $12 \sim 52 \mathrm{mg} / \ell$ and the average COD was $100.3 \mathrm{mg} / \ell$. There were several cases when the water quality of the influent was too high. There were many cases of process using a lot of starch for advancement of the paper. When the change of water quality was serious, bubbles would occur where there was difficulty in operating and managing the reactor. Also, the treated water quality also increased where the water quality was comparatively high. However, the microorganisms accommodated from the wastewater treatment in Company $\mathrm{M}$ was used for the experiment where the removal efficiency of the COD was maintained constantly.

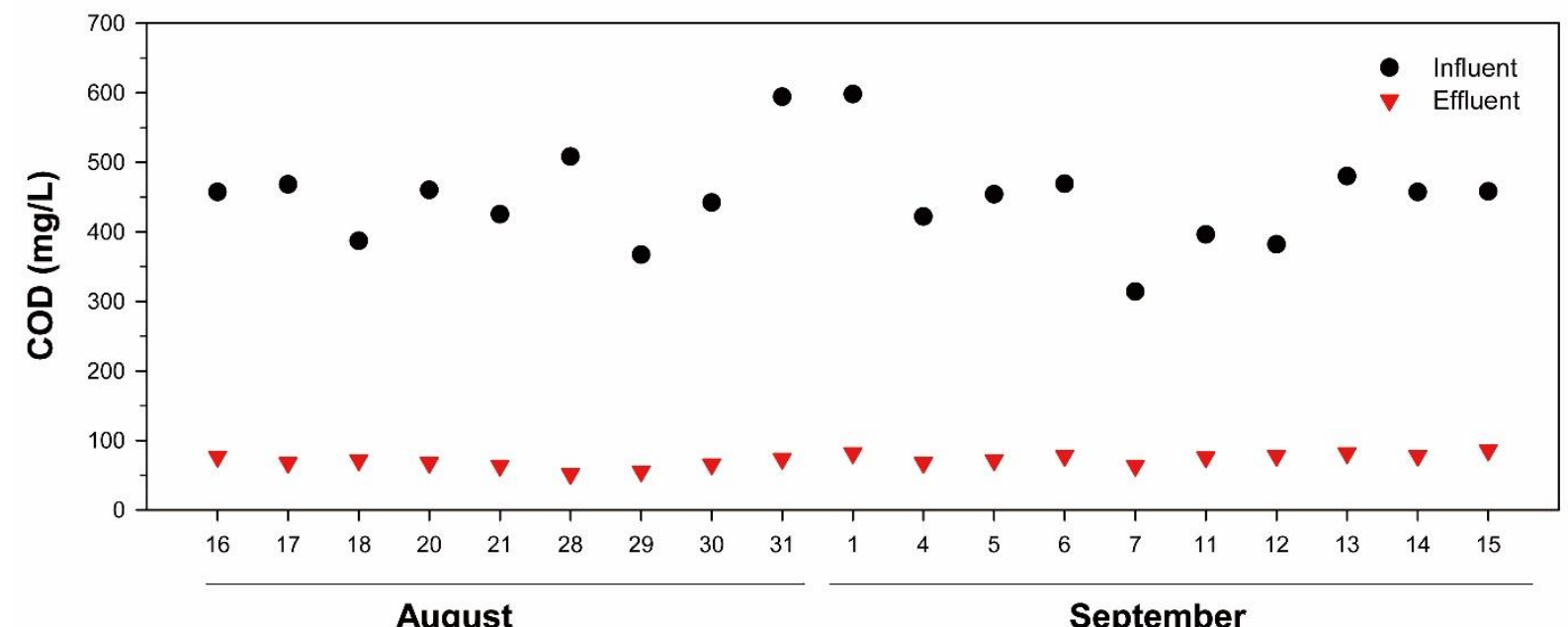

Figure 6. Profiles of COD concentration of paper-mill wastewater and permeate water 


\subsubsection{Change of MLSS on the SMBR Bioreactor}

Figure 7 shows the experiment result of the MLSS concentration change when the HRT was $4.4 \mathrm{hrs}$. The MLSS concentration within the SMBR reactor maintained average of $3,026 \mathrm{mg} / \ell$. To constantly maintain the MLSS concentration, the PLC program controlled to discharge the concentrated MLSS 2 times a day was used. Due to this, the MLSS within the reactor was maintained constantly to 3,026 $\mathrm{mg} / \ell$, but the SMBR bioreactor's microorganism increase and the control of the pullout amount according to concentration was the core factor to the stable MLSS management to acquire stable treated water quality.

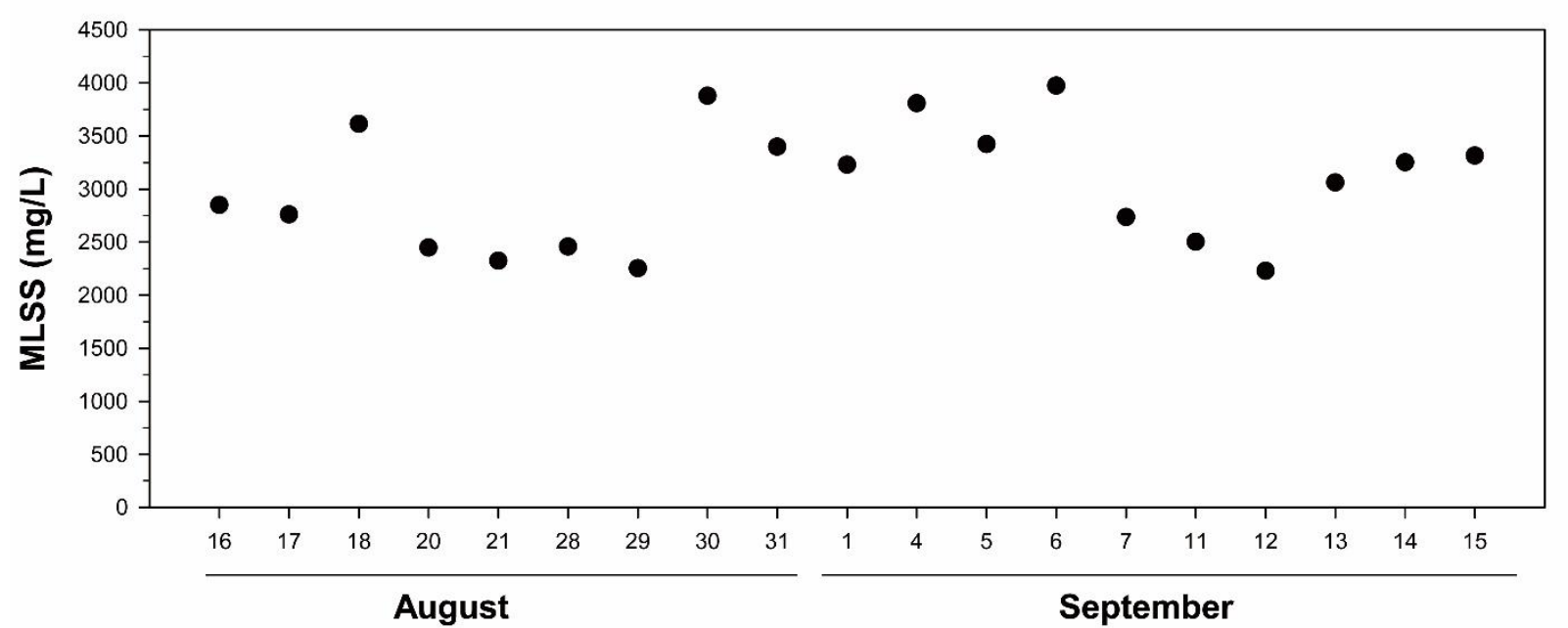

Figure 7. Profiles of MLSS concentration with operating days

\subsection{Ozone Oxidation Experiment on the Effluent of MBR Bioreactor}

\subsubsection{Absorption Wavelength Analysis of Ozone Oxidation of MRB Biotreated Water}

$\mathrm{UV}_{254}$ Scan analysis method is used as an analysis method of judging the conditions of whether or not a lot of aromatic chemical substance exists on the raw water. This study used the diaminostilbene disulfonic acid derivative for the paper in the paper-mill factory in the process of manufacturing paper in the Company M paper-mill factory[20] and it has been contained in the water quality of the effluent after biotreatment where the experiment was done based on the effluent from the MBR bioreactor. The Diaminostilbene disulfonic acid fluorescent pigment used often in the paper mill industry and the dye industry is an aromatic chemical substance oxidized from the p-nitrotoluene and is a fluorescent whitening agent. The maximum absorption wavelength before oxidization of the diaminostilbene disulfonic acid derivative showed maximum peak of $280 \mathrm{~nm}$. This reported $280 \sim 330 \mathrm{~nm}$ or $355 \mathrm{~nm}$ for the range of the diaminostilbene disulfonic acid derivative[21]. When looking at the result of Figure 8, which analyzed the wavelength in the $\mathrm{UV}_{254}$ Scan due to the ozone oxidation, the greatest peak was shown in around $280 \mathrm{~nm}$ maximum wavelength. The aromatic chemical substance fluorescent pigment in the fluorescent dye and organic chemical substances in the paper-mill wastewater in the $280 \mathrm{~nm}$ existed. Reduction of the maximum wavelength was identified after $10 \mathrm{~min}$ from the initial starting point of the ozone oxidation. This can be predicted that the fluorescent whitening agent characteristic was lost while around $99 \%$ of the chromophore of the fluorescent pigment was removed. After $20 \mathrm{~min}$, there was oxidation where almost all the fluorescent whitening effect was removed. Therefore, the completion for decomposition of the fluorescent whitening agent in the effluent that passed the SMBR bioreactor took 20 
min. Based on the $\mathrm{UV}_{254}$ scan result, it appeared that $6.67 \mathrm{~g}-\mathrm{O}_{3} / \mathrm{min}$ of ozone amount was needed to remove the fluorescent whitening agent through the ozone oxidation of the actual wastewater.

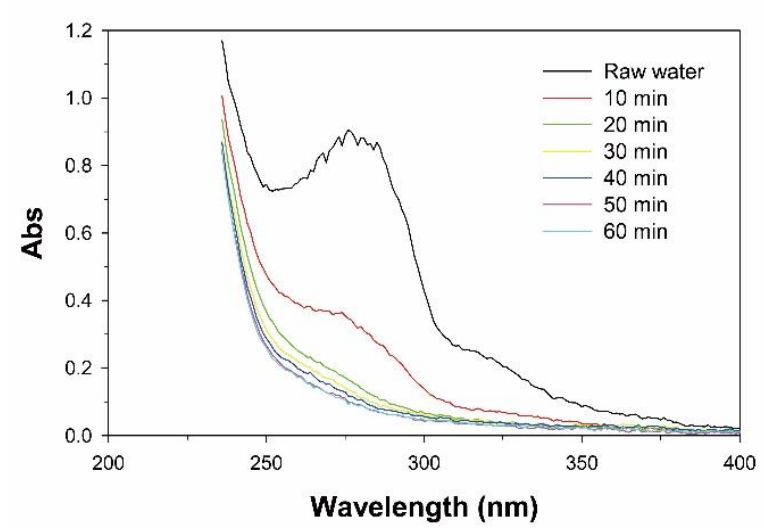

Figure 8. Effect of ozone oxidation of fluorescent whitening agents on $\mathrm{UV}_{254}$ scan

\subsubsection{Change of Organic Pollutants due to Ozone Oxidation of SMBR Biotreated Water}

Experiment was executed on the ozone oxidation based on the discharged water that passed SMBR biotreatment. The organic pollutant concentration was measured and the results are shown in Figure 9. The used amount of fluorescent whitening agent used in the composition process of the manufacturing process of Company M's paper was calculated to around $7 \mathrm{mg} / \ell$ when calculating the amount through fluorescent whitening agent use and total use of COD concentration. The total amount of other pollutants of the effluent showed initial COD of $61.5 \mathrm{mg} / \ell$ measured every $10 \mathrm{~min}$. The ozone oxidation experiment was executed for a total of $60 \mathrm{~min}$. In the first $10 \mathrm{~min}$ of ozone oxidation, the destruction of amino acid of the chromophore occurred. In this serial process, the continuous process of oxidation reduction was judged to be intensively executed. After $20 \mathrm{~min}$ of reaction, the oxidation speed relatively slowed down. After the completion of reaction, the COD was $14 \mathrm{mg} / \ell$. Based on this result and as a result of experimenting ozone oxidation on the MBR biotreated water, the ozone input needed when connecting to biotreat the paper-mill wastewater was $6.67 \mathrm{~g}-\mathrm{O}_{3} / \mathrm{min}$. Here, the change of the intermediate compounds that induce the COD evaluated on the change of COD and TOC concentration resulted in the reaction of removing the sulfone and amino of the fiber or paper and the fluorescent whitening agent within $10 \mathrm{~min}$ of the ozone oxidation reaction time in the oxidation experiment of the diaminostilbene disulfonic acid derivative. After rapidly reacting with the ozone, the creation of aldehyde and methyl started[22-24]. From the 20 min point, complete separation of the diaminostilbene sulfonic acid was continued and from the 30 min point, around $72.3 \%$ was removed. Based on this, the COD removal amount on the ozone input on the effluent treated and discharged from the SMBR Bioreactor including the fluorescent whitening agent was calculated to be $0.997 \mathrm{mg}$-COD of the $1 \mathrm{mg} \mathrm{O}$. 


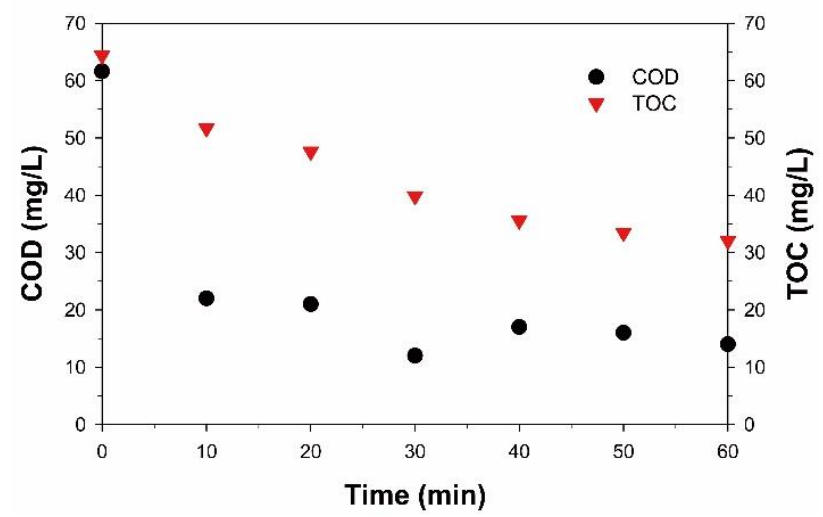

Figure 9. Effect of ozone oxidation of the paper and papermill wastewater contained fluorescent whitening agents on COD and TOC

\section{Conclusion}

As a method to acquire reusable water from the paper-mill wastewater, research by combining submerged membrane bioreactor filtration and ozone oxidation process was executed. The operation condition of the SMBR was MLSS $2200 \pm 4000 \mathrm{mg} / \mathrm{L}, 25 \sim 50 \mathrm{~m}^{3} / \mathrm{min}$ for aeration strength, $4.4 \mathrm{hrs}$ for HRT, 6.5 days for SRT, and $1.5 \mathrm{l} / \mathrm{min}$ with differential pressure set to $0.032 \mathrm{bar}$. The following is the result on executing the Ozone Oxidation Experiment on the filtrated water of the MBR Bioreactor.

- The average turbidity of the paper-mill wastewater was 327 NTU where the turbidity of the filtrated water of the SMBR bioreactor was average of 1.1 NTU bringing around $99 \%$ of removal efficiency.

- As a result of investigating and analyzing the organic contaminant change of the paper-mill wastewater, the average COD was $449.3 \mathrm{mg} / \ell$ where the COD of the average filtrated water after SMBR biotreatment was $100.3 \mathrm{mg} / \ell$ bringing around $70.1 \%$ of removal efficiency.

- The ozone amount needed to remove the fluorescent whitening agent remaining in the filtrated water that passed SMBR of the paper-mill wastewater was $6.67 \mathrm{~g}-\mathrm{O}_{3} / \mathrm{min}$.

- The COD removal amount on the ozone input on the effluent of the SMBR bioreactor was calculated to remove $0.997 \mathrm{mg}-\mathrm{COD}$ of $1 \mathrm{mg} \mathrm{O}$.

Acknowledgement: This subject is supported by Korea Ministry of Environment as "Global Top Project"(Project No.:2016002210001)

\section{References}

1. Hoekstra, A.Y. Human appropriation of natural capital: A comparison of ecological footprint and water footprint analysis. Ecol. Econ. 2009.

2. Korean Ministry of Environment Water reuse master plan; Seoul, South Korea, 2011; 
3. National Institute of Environmental Research Occurrence and treatment of factory wastewater; Seoul, South Korea, 2013;

4. Lim, G.B.; Lee, J.Y.; Kim, C.H.; Kim, S.Y.; Park, J.H. Study on the Factors Influencing the Fluorescence Index of Internal Fluorescent Whitening Agent. J. Korea Tech. Assoc. Pulp Pap. Ind. 2014, 46, 11-12.

5. Oller, I.; Malato, S.; Sánchez-Pérez, J.A. Combination of Advanced Oxidation Processes and biological treatments for wastewater decontamination-A review. Sci. Total Environ. 2011.

6. Kim, D.H. A Study on the Advanced Wastewater Treatment using Cartridge Filter-Type MF Membrane and Intermittent Aeration. J. Korean Soc. Environ. Eng. 2001, 23, 1035.

7. Kim, K.J.; Yoon, S.H. Wastewater Treatment Using Membrane Bioreactor(MBR). J. Korean Ind. Eng. Chem. 2001, 12, 239.

8. Mayhew, M.; Stephenson, T. Low biomass yield activated sludge: A review. Environ. Technol. (United Kingdom) 1997.

9. Asano, T.; Burton, F.L.; Leverenz, H.L.; Tsuchihashi, R.; Tchobanoglous, G. Water Reuse: Issues, Technologies, and Applications; 2007; ISBN 0036-7672 (Print)r0036-7672 (Linking).

10. Cho, I.H.; Kim, J.T. Trends in the technology and market of membrane bioreactors (MBR) for wastewater treatment and reuse and development directions. Membr. J. 2013, 23, 24-44.

11. Karat, I. Advanced Oxidation Processes for Removal of COD from Pulp and Paper Mill Effluents, Royal Institute of Technology in Stockholm, 2013.

12. Shin, H.S.; Lim, J.L. Improving Biodegradability of Naphthalene Refinery Process Wastewater by Ozonation. J. Korean Soc. Environ. Eng. 1993, 15, 478.

13. Kim, C.H.; Lee, J.Y.; Kim, B.H.; Choi, J.S.; Lim, G.B.; Kim, D.M. Study on the thermal fastness of fluorescent whitening agents. J. Korea Tech. Assoc. Pulp Pap. Ind. 2012, 44, 10-11.

14. Zhang, H.; He, Z.; Ni, Y.; Hu, H.; Zhou, Y. Using Optical Brightening Agents (OBA) for Improving the Optical Properties of HYP-Containing Paper Sheets. Pulp Pap. Canada 2009, 110, 20.

15. National Institute of Environmental Research Survey on Exposure of Fuorescent Bightener Agents by products; Seoul, South Korea, 2007;

16. Lesjean, B.; Gnirss, R. Grey water treatment with a membrane bioreactor operated at low SRT and low HRT. Desalination 2006.

17. Rice, E..; Baird, R.B.; Eaton, A.D. Standard Method for Examination of Water and Wastewater; 19th ed.; APHA, AWWA and WPCF: Washington DC, USA, 1995;

18. Sumikura, M.; Hidaka, M.; Murakami, H.; Nobutomo, Y.; Murakami, T. Ozone micro-bubble disinfection method for wastewater reuse system. In Proceedings of the Water Science and Technology; 2007.

19. Shin, H.S.; An, H.H.; Kang, S.T. Fouling Factors in Submerged Membrane Bioreactor (1). J. Korean Soc. Water Qual. 1999, 15, 415-420.

20. Jung, Y.; Bae, J.; Min, K. Reuse of Weaving Wastewater by Membrane Bioreactor Equipped with a Hollow-Fiber MF Membrane. J. Korean Soc. Water Qual. 2004, 20, 365-369.

21. Cho, B.U.; Won, J.M. Effect of PVAm Application for Fine Paper on Effectiveness of Optical Brightening Agent. J. Korea Tech. Assoc. Pulp Pap. Ind. 2016, 48, 24.

22. Chin, I.J.; Jang, C.S. Characterization of Epoxy Cure by Chromophore Labeling Technique. Polymer(Korea) 1990, 14, 285.

23. Kim, S.S.; Huh, M.W.; Han, M.H.; Yoon, J.H.; Cho, H.; Kim, D.K. A Study On The Decomposition Properties Of Disperse Dye Ozone Oxidation Treatment and The Optimum Treatment Condition(I). J. Korea Soc. Dye. Finish. 1996, 8, 45.

24. Peng, W.; Chen, Y.; Fan, S.; Zhang, F.; Zhang, G.; Fan, X. Use of 4, 4'-Dinitrostilbene-2, 2'Disulfonic Acid Wastewater As a Raw Material for Paramycin Production. Environ. Sci. Technol. 2010, 44, 9159. 